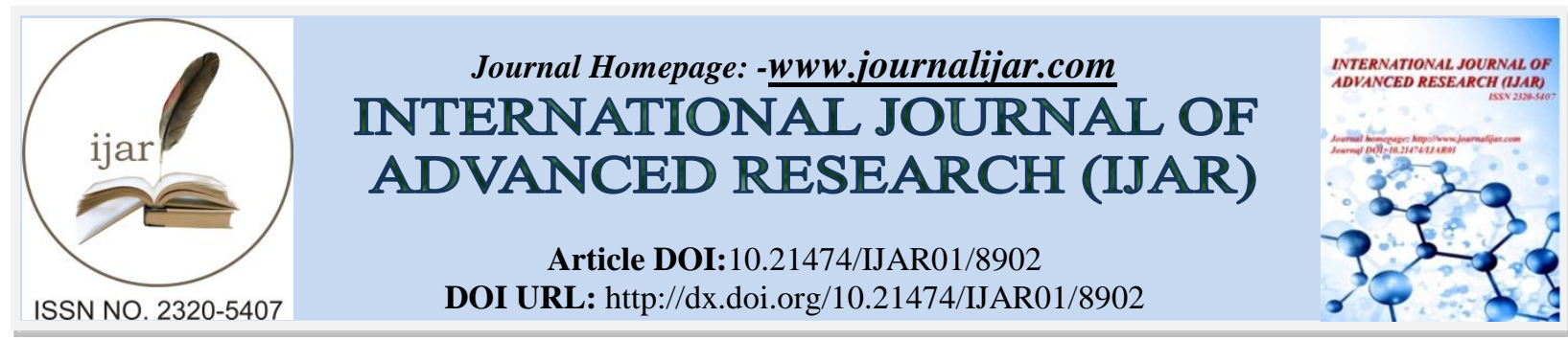

RESEARCH ARTICLE

\title{
DESIGN AND DEVELOPMENT OF AUTOMATED ACCIDENT PREVENT SYSTEM.
}

Prabu $\mathbf{P}^{1}$, Praveenraj $\mathbf{G}^{\mathbf{1}}$, Sureshkumar $\mathrm{K}^{\mathbf{1}}$, Thiruvarasamoorthi $\mathbf{R}^{\mathbf{1}}$, A. Mahabubadsha ${ }^{2}$ and $\mathrm{K}$. Anandavelu ${ }^{3}$. 1. Students Mechanical Engineering, M R K Institute of Technology, Kattumannarkoil, Tamilnadu, India.

2. Assistant Professor, Mechanical Engineering, M R K Institute of Technology, Kattumannarkoil, Tamilnadu, India.

3. Professor, Mechanical Engineering, M R K Institute of Technology, Kattumannarkoil, Tamilnadu, India.

\section{Manuscript Info}

\section{Manuscript History}

Received: 12 February 2019

Final Accepted: 14 March 2019

Published: April 2019

\section{Abstract}

Our project control system based intelligent electronically controlled automotive bumper activation and automatic pneumatic braking system is called "Automated Accident Prevents System". Our main aim of the project is reduce the vehicle accident and also reduce the death rate of the human being with the help of the IR sensor circuit, Control Unit, Pneumatic bumper system and pneumatic braking system. The IR sensor senses the obstacle. There is any obstacle closer to the vehicle the control signal is given to the bumper activation system and also pneumatic braking system simultaneously. The pneumatic bumper and braking system is used to reduce the vehicle damage as well as human life. This bumper and braking activation system is only activated the vehicle speed above $25-30 \mathrm{~km}$ per hour. This vehicle speed is sensed by the Passive infrared sensor and this signal is given to the control unit and it activate the bumper and breaking system.

Copy Right, IJAR, 2019,. All rights reserved.

\section{Introduction:-}

Today India is the most important under developed country in the world. India is the largest country in the use of various types of vehicles. As the available resources to run these vehicles like quality of roads, and unavailability of new technologies in vehicles are causes for accidents. The number of peoples which are dead during the vehicle accidents is also very large as compared to the other causes of death. Though there are different causes for these accidents but proper technology of braking system and technology to reduce the damage during accident are mainly affects on the accident rates. So today implementation of proper braking system to prevent the accidents and pneumatic bumper system to reduce the damage of the vehicles. We have pleasure in introducing our new project "AUTOMATED ACCIDENT PREVENTS SYSTEM", which is fully equipped by IR sensors circuit and Pneumatic activation circuit.

The Indian government has released the official statistics for road accidents, inju ries and fatalities for the year 2017, and the news continues to be bad. As per the latest data, in 2017, a total of 464910 road accidents were reported in the country, claiming 147913 lives and causing injuries to 470975 persons, which translates into 405 deaths and 1,290 injuries each day from 1274 accidents. This also means that 16 people are killed and another 53 are injured every hour on Indian roads.

Corresponding Author:-Prabu P.

Address:-Students Mechanical Engineering, M.R.K Institute of Technology, Kattumannarkoil,

Tamilnadu, India-608301. 


\section{Problem Statement}

In conventional vehicles there are different mechanism operated for braking system like hydraulic, pneumatic, air, mechanical, etc. But all these braking mechanisms receive the signal or input power directly from the driver so it totally manual operated. When the driver saw the obstacle or any vehicle in front of his driving vehicle, he was irritated or becomes mazy. Due to this the driver fails to give the proper input to braking system and proper working is not occurs. Also the driver may not able to pay the full attention during night travelling so there are many chances to accidents. After the accident occurs, there is no any provision to minimize the damages of vehicles. In currently used vehicles generally bumpers used are of rigid types. These bumpers have specific capacity and when the range of the accidental force is very high then the bumpers are fails and these force transferred towards the passengers. So this system never reduces the damage of both vehicle and passengers. To overcome these unwanted effects design the Automatic Pneumatic Bumpers is important.

\section{Parts To Be Used \\ Pneumatic cyclinder}

The cylinder is a Double acting cylinder one, which means that the air pressure operates forward and spring returns backward. The air from the compressor is passed through the regulator which controls the pressure to required amount by adjusting its knob. A pressure gauge is attached to the regulator for showing the line pressure. Then the compressed air is passed through the double acting5/2 solenoid valve for supplying the air to one side of the cylinder. One hose take the output of the directional Control (Solenoid) valve and they are attached to one end of the cylinder by means of connectors. One of the outputs from the directional control valve is taken to the flow control valve from taken to the cylinder. The hose is attached to each component of pneumatic system only by connectors.

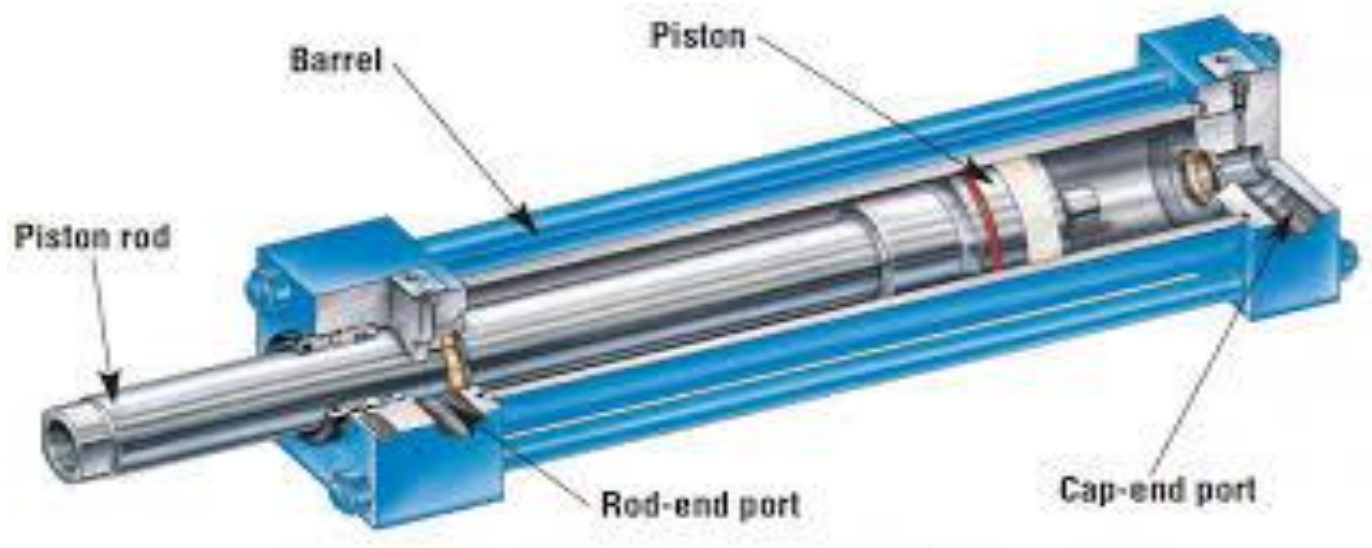

\section{Solenoid valve}

The directional valve is one of the important parts of a pneumatic system. Commonly known as DCV, this valve is used to control the direction of air flow in the pneumatic system. A solenoid is an electrical device that converts electrical energy into straight line motion and force. These are also used to operate a mechanical operation which in turn operates the valve mechanism. Solenoids may be push type or pull type. The push type solenoid is one in which the plunger is pushed when the solenoid is energized electrically. The pull type solenoid is one is which the plunger is pulled when the solenoid is energized. Solenoid and spring mechanisms are used to displace the spool valve in case of the solenoid actuation directional valve (or simply solenoid directional valve) solenoid actuation can also be used with 5/2 ways directional valve. There are three connections, or valve ports, labelled as A, B and C, respectively. As long as the valve remains in the left position, left rectangle, there is airflow from port $\mathrm{A}$ to $\mathrm{C}$, while port $\mathrm{B}$ is blocked. When this valve is shifted to its right position, right rectangle, port A blocked, while port B and C are connected. The arrowheads shown on the symbol are optional, they indicating the airflow directions. These are also used to operate a mechanical operation which in turn operates the valve mechanism.

\section{Ir sensor unit:}

The IR transmitter and IR receiver circuit is used to sense the obstacle. It is fixed to the back side of the frame stand with a suitable arrangement. The pneumatic cylinder is controlled by the flow control valve, double acting solenoid valve and control unit. 


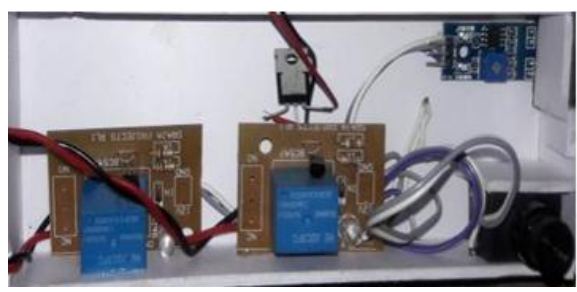

\section{Normal condition:}

The IR transmitter sensor is transmitting the infrared rays with the help of 555 IC timer circuit. These infrared rays are received by the IR receiver sensor. The Transistor T1, T2 and T3 are used as an amplifier section. At normal condition Transistor T5 is OFF condition. At that time relay is OFF, so that the vehicle running continuously.

\section{Obstacle Condition:}

At Obstacle conditions the IR transmitter and IR receiver, the resistance across the Transmitter and receiver is high due to the non-conductivity of the IR waves. So the output of transistor T5 goes from OFF condition to ON stage. In that time the relay is ON position. In that time, the solenoid valve is on so that the vehicle stops.

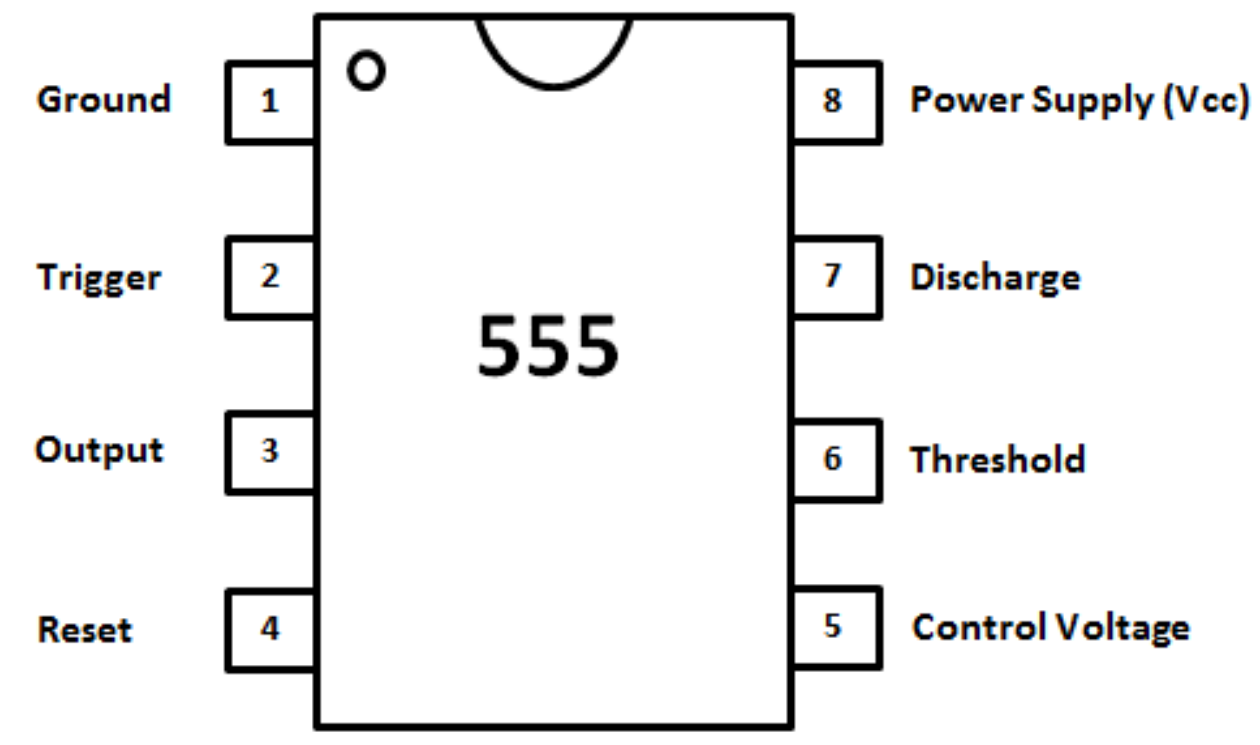

\section{IC 555 TIMER}

The IC SE / NE 555 monolithic circuit is a highly stable controller capable of producing accurate time delays or oscillations. Additional terminals are provided for triggering or resetting if desired. both accurately contributed with the external RC constants.

PIN NO: 1 it is ground terminal.

PIN NO: 2 the trigger voltage to the lower comparator is applied. It has constant voltage that is at least one third of the supply voltage, when trigger voltage falls below this level the flip-flop changes its state and output becomes high.

PIN NO: 3 It is the output terminal, in low state output is equal to zero and when at higher state output is equal to Vcc.

PIN NO: 4 It controls the flip flop directly. It turns the device to its original position when reset pin is connected to ground the output is approximately equal to zero. When reset is not used it is connected to Vcc.

PIN NO: 5 It is the control voltage terminal. It is connected to ground through a capacitor of $0.01 \mu \mathrm{F}$. Any external voltage at pin: 5 will change both the threshold voltage and the trigger voltage reference level. 
PIN NO: 6Threshold voltage of upper comparator is applied from this terminal. The resistor $\mathrm{R}_{\mathrm{t}}$ connected to Vcc and pin: 6 is grounded by an external capacitor. The output is high capacitor charges by resistor Rt. When the capacitor changes to the threshold level, the output becomes low.

PIN NO: 7 It is the discharge pin for external capacitor. Usually pin: 7 is connected with pin: 6 directly to by a resistor. When the output becomes low then the external capacitor discharges by internal discharge transistor remains at cut-off and the external capacitor charges to Vcc.

PIN NO: 8 It is the positive supply terminal. A dc voltage from +5 to +15 can be applied. The important features of IC555 can be summarized as follows.

\section{Battery}

The battery is an essential component of almost all aircraft electrical systems. Batteries are used to start engines and auxiliary power units, to provide emergency backup power for essential avionics equipment, to assure no-break power for navigation units and fly-by-wire computers, and to provide ground power capability for maintenance and preflight checkouts. Many of these functions are mission critical, so the performance and reliability of an aircraft battery is of considerable importance. Other important requirements include environmental ruggedness, a wide operating temperature range, and ease of maintenance, rapid recharge capability, and tolerance to abuse.

\section{Air Compressor System}

A compressed air supply within a manufacturing plant or an automotive collision and body shop often consists of one compressor that can meet the overall air requirements. Makes sense, right? But consider an alternative: multiple smaller horsepower compressors positioned at strategic points throughout the plant or shop. These compressors would feed into a common air line or into individual lines serving one or more points of use. In the central system, the compressor is of a size to supply total compressed air requirements, at least in the beginning. This option has the advantage of one compressor, one point of maintenance, and one electric power connection. The potential disadvantage is the requirement of more piping, which causes the system to be costly to install and more costly to maintain. In the alternate system, the plant or shop starts with a single small compressor installation. Then, as expansion takes place, instead of replacing the single unit with a larger capacity single unit, another unit of the same size is installed. Initial cost is less in the smaller multiple units than in the larger central unit. Maintenance cost is less, and cost of operation is also less, since each unit operates independently of the others. This is the optimum compressor installation-one that has the lowest installation, maintenance, and operating costs, and also the flexibility to meet changing requirements of a shop or plant. Hence, many plants have started to follow the trend towards smaller multiple compressor units. Further advantages of multiple units are: one standby compressor can serve a number of departments; units are complete and ready for electric and air piping connections; no special foundation is required; units are usually air cooled, thus saving on water and installation cost; and units are easily moved from place to place. In addition, smaller units can meet a plant's special, occasional, or part-time requirements, with notable savings in cost of operation.

\section{Frame}

It is fully made of mild steel. Wheels are fitted in the frame. All the components are mounted in the frame. Such as motor, battery and etc..

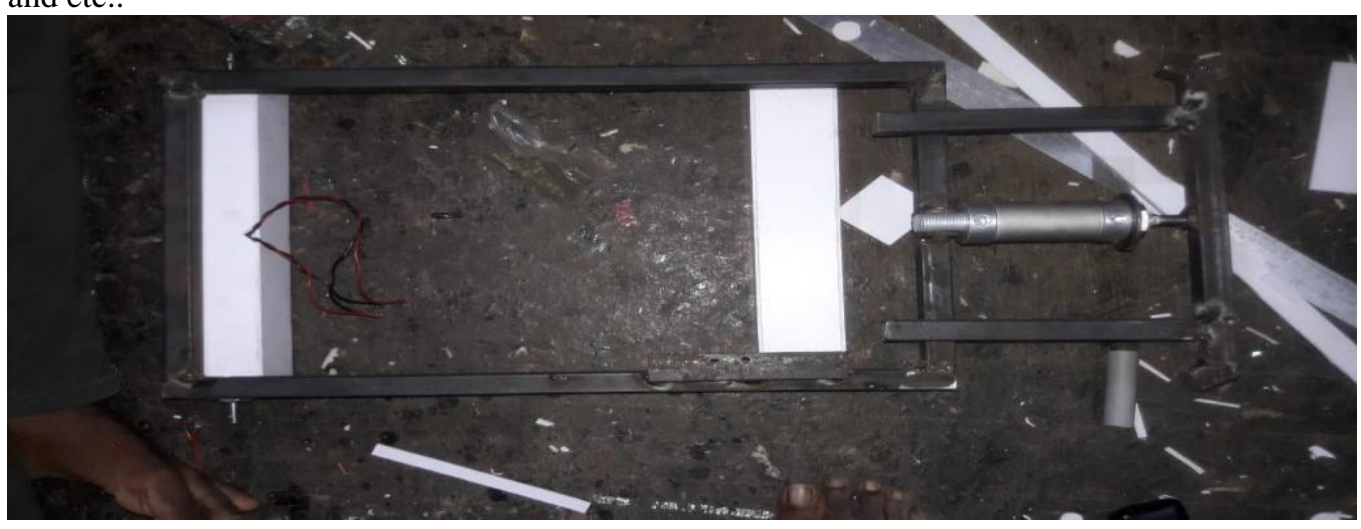




\section{Puconnectiors, Reducer And Hosecollar}

In our pneumatic system there are two types of connectors used; one is the hose connector and the other is the reducer. Hose connectors normally comprise an adapter (connector) hose nipple and cap nut. These types of connectors are made up of brass or Aluminium or hardened steel. Reducers are used to provide inter connection between two pipes or hoses of different sizes. They may be fitted straight, tee, "V" or other configurations. These reducers are made up of gunmetal or other materials like hardened steel etc.

\section{Working Principle}

The sensor fitted in the bumper of the vehicle. The vehicle speed more than the $25-30 \mathrm{kmph}$ when the IR sensor system is actuated. The sensor senses the obstacle and generates output signal. Then it sends signal to the solenoid direction control valve and it gets actuated. The solenoid direction control valve is used in this system. When it gets signal and opens the pneumatic valve as a result it pushes the piston forward along- with flexible bumper and the breaking arrangement is used to break the wheel gradually or suddenly due to the piston movement. The breaking speed is varied by adjusting the valve is called "FLOW CONTROL VALVE". There by due to compressible properties it absorbs the sudden shocks on vehicle chassis and releases when obstacle rare.

\section{Flow Chart}
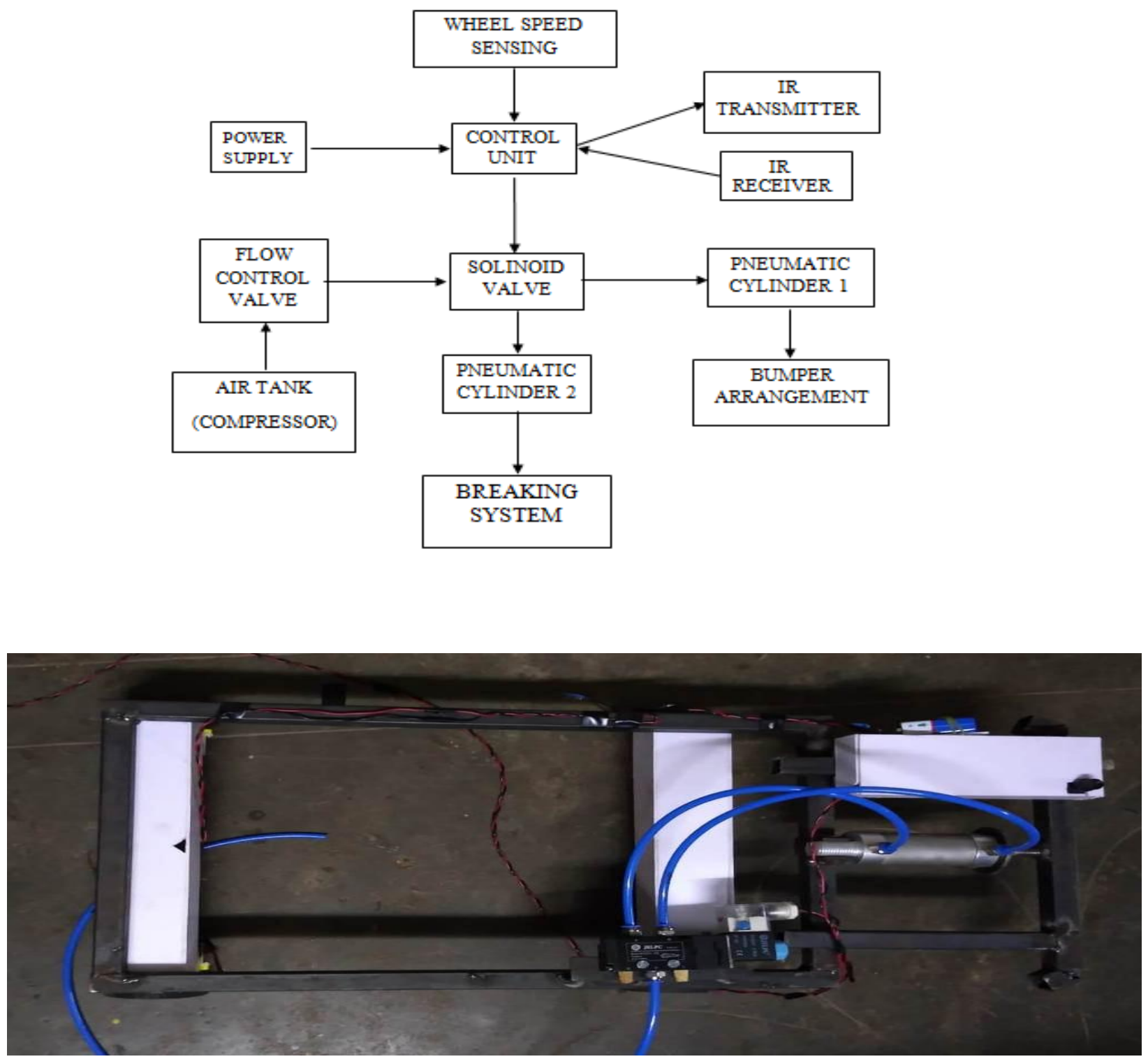

Our project 


\section{Calculation:}

Cylinder force

$$
\begin{aligned}
\mathrm{F} & =\mathrm{p} \mathrm{A} \\
& =\mathrm{p} \pi \mathrm{d}^{2} / 4
\end{aligned}
$$

Where

$\mathrm{F}=$ force exerted $(\mathrm{N})$

$\mathrm{p}=$ gauge pressure $\left(\mathrm{N} / \mathrm{m}^{2}, \mathrm{~Pa}\right)$

$\mathrm{A}=$ full bore area $(\mathrm{m}$

$\mathrm{d}=$ full bore piston diameter (

$$
\begin{aligned}
& \mathrm{p}=5 \mathrm{bar} \\
& \mathrm{d}=25 \mathrm{~cm} \\
& \mathrm{~F}=5 \times\left(\pi \times 25^{2} / 4\right) \\
& \mathrm{F}=24544 \mathrm{~N}
\end{aligned}
$$

Impact force

$$
\begin{aligned}
& \text { Impulse }=\mathrm{F}_{\text {average }} \Delta \mathrm{t}=\mathrm{m} \Delta \mathrm{v} \\
& \mathrm{F}_{\text {average }}=\mathrm{m} \Delta \mathrm{v} / \Delta \mathrm{t}
\end{aligned}
$$

$$
\begin{aligned}
& \text { Where } \\
& \begin{array}{c}
\mathrm{F}_{\text {average }} \text { - Impact fo } \\
\text { M-mass of vehicl } \\
\Delta \mathrm{v} \text {-change in vel } \\
\Delta \mathrm{t} \text {-impact } \\
\mathrm{m}-1400 \mathrm{~kg} \\
\Delta \mathrm{t}-2 \mathrm{se} \\
\Delta \mathrm{v}-8.33 \mathrm{~m} / \mathrm{sec} \\
\mathrm{F}_{\text {avg }}=(1400 \mathrm{x} 8.33) / 2 \\
\mathrm{~F}_{\text {avg }}=5831 \mathrm{~N} \\
\text { Impact force }=11662 \mathrm{~N}-\mathrm{Sec}
\end{array}
\end{aligned}
$$

\section{Specification}

Piston cylinder specification:

Stroke length: $25 \mathrm{~mm}$ diameter

Diameter: $25 \mathrm{~mm}$

Pull force capacity: up-to $15 \mathrm{~kg}$

\section{Direction control valve specification:}

$5 * 2 \mathrm{DCV}$

Actuation: solenoid operated DC coil

Coil voltage ratings: 12 volt ( $0.5 \mathrm{amp}$ to $2 \mathrm{amp}$ )

\section{Specification of compressor:}

Type: Rotary air compressor

Input voltage: 12 volt $2.5 \mathrm{amp}$

Output pressure: 3 bar capacity

Discharge: $25 \mathrm{~cm} 3 / \mathrm{s}$

\section{Material used for chassis:}

Square mild steel pipe of $20 \mathrm{~mm} \times 20 \mathrm{~mm}$

\section{Battery:}

Output: 12 volt 2.5 amp dc supply. 


\section{Drive:}

Dc motor

Input: 12 volt $1 \mathrm{amp}$

Speed: $30 \mathrm{rpm}$

\section{Conclusion:-}

The aim is to design and develop a control system based on pneumatic breaking system of an intelligent electronically controlled automotive braking system. Based on this model, control strategies such as an 'PNEUMATIC BREAKING' and improved manoeuvrability via individual wheel braking are to be developed and evaluated. Our project gives opportunity to prevent low speed accident. And it used to decrease the impact force of the vehicle. And it also save the passengers life and it also reduce the force transfer to human

\section{Reference:-}

1. SrinivasaChari.V, Dr.Venkatesh P.R, Dr.PrasannaRao N.S, Adil Ahmed S “Automatic Pneumatic Bumper And brake Actuation Before Collision”, 2015, International Research Journal Of Engineering And Technology (Irjet) Volume: 02 Issue: 04, Pp1015-1023

2. Dr. P. Poongodi. Mr. P. Dineshkumar, "Automatic Safety System For Automobiles"

3. Jadhav N. D., Gulmire S.M., Ghutukade R.S., Gaikwad A.S., Prof.Fegade S.G. "Automatic Braking With Pneumatic Bumper System" 2015,Ijsart Volume 1 Issue 5, Pp

4. Jadhav N. D., Gulmire S.M., Ghutukade R.S., Gaikwad A.S., Prof.Fegade S.G. "Automatic Braking With Pneumatic Bumper

5. System" 2015,Ijsart Volume 1 Issue 5, Pp. 